\section{Is it necessary to perform appendicectomy in the middle of the night in children?}

\author{
Rajendra Surana, Feargal Quinn, Prem Puri
}

Our Lady's Hospital for Sick Children, Crumlin, Dublin 12, Ireland Rajendra Surana, senior registrar, paediatric surgery Feargal Quinn, senior registrar, paediatric surgery Prem Puri, consultant paediatric surgeon

Correspondence to: Mr Puri.

$B M 7$ 1993;306:1168
( $p=0 \cdot 21 ; 95 \%$ confidence interval $-3 \cdot 7 \%$ to $8 \cdot 7 \%$ ).

Postoperative complications occurred in 18 patients $(4 \%)$ in the group operated on within six hours and 12 $(5 \%)$ patients in the group operated on 6-18 hours after admission (table). Wound infections were treated

Postoperative complications in children undergoing appendicectomy

Early appendicectomy has been the treatment of choice for acute appendicitis. The report of a confidential inquiry into perioperative deaths (CEPOD) in the United Kingdom has shown that there is increased reluctance to involve senior members of the staff in the night, resulting in a lower standard of care which is reflected by inappropriate preoperative management, inappropriate operation, and deaths related to surgery. ${ }^{1}$ It is generally accepted that delay in appendicectomy is associated with increased risk of perforation, complications, and prolonged hospitalisation. Advances in preoperative fluid and electrolyte management, anaesthesia, and antimicrobial prophylaxis, especially against anaerobes, have resulted in decreased morbidity in appendicitis. ${ }^{2}$ It is increasingly realised that sleep deprivation in surgical and anaesthetic junior hospital staff causes significant reduction in performance of mental and physical skills. ${ }^{3}$ With these factors in mind we compared the outcome in children with appendicitis who underwent early appendicectomy with that in those whose operation was delayed overnight.

\section{Materials, methods, and results}

We audited outcome in patients who had emergency appendicectomy between January 1987 and December 1991. Patients were divided into two groups: those who had an appendicectomy within six hours of admission and those observed overnight and who had an appendicectomy 6-18 hours after admission. It is hospital policy that all patients with acute appendicitis who cannot be operated on before midnight are operated on the following morning.

Antibiotics were given before operation in all patients. Amoxycillin with clavulinic acid was given for up to 48 hours to patients with acute appendicitis and gentamicin with metronidazole for up to seven days to patients with perforated appendicitis. All wounds were closed primarily in layers with absorbable subcuticular sutures.

We estimated that 230 patients would be needed in each group to obtain a sample with $80 \%$ power and $10 \%$ difference in incidence of perforation $(20 \% v 30 \%)$. The $\mathrm{Z}$ test, two tailed for age and one tailed for perforation and complications, was used for statistical analysis.

This study included 695 patients -451 (257 boys) operated on within six hours and 244 (128 boys) operated on 6-18 hours after admission. Mean (SD) age was $9.9(2.7)$ years and $10.1(2.8)$ years respectively $(p=0.363)$. Diagnoses included acute appendicitis in $325(72 \%)$ patients, perforated appendix in $81(18 \%)$, and normal appendix in $45(10 \%)$ in the group operated on within six hours and $169(69 \%), 50(21 \%)$, and 25 $(10 \%)$ in the group whose operation was delayed. The difference in the rate of perforation was not significant

\begin{tabular}{|c|c|c|}
\hline Complications & $\begin{array}{c}\text { Operation within } \\
6 \text { hours } \\
(n=451)\end{array}$ & $\begin{array}{l}\text { Operation } 6-18 \text { hours } \\
\text { after admission } \\
(n=244)\end{array}$ \\
\hline \multicolumn{3}{|l|}{ Minor: } \\
\hline Wound infection & 6 & 5 \\
\hline Ileus & 2 & 1 \\
\hline \multicolumn{3}{|l|}{ Major: } \\
\hline Intra-abdominal abscess & 8 & 4 \\
\hline Adhesive obstruction & 2 & 2 \\
\hline Total & $18(4 \cdot 0 \%)$ & $12(4.9 \%)$ \\
\hline
\end{tabular}

by local drainage, dressings, and antibiotics without resuturing or debridement of wounds. Eight patients with intra-abdominal abscesses responded to antibiotics, one patient from each group required peroperative drainage. One patient with intestinal obstruction from each group failed to respond to conservative management and required laparotomy and adhesiolysis. There was no statistical difference in the rate of complications in the two groups $(p=0.28$; $-2 \cdot 3 \%$ to $4 \cdot 2 \%$ ).

The average hospital stay for the group operated on within six hours was 3.5 (range 2-18) days compared with $4 \cdot 1(2-21)$ days for the group whose operation was delayed. There were no deaths.

\section{Comment}

Our data show that the rate of appendiceal perforation and complications in two groups were similar and compare favourably with the recently published reports where the emphasis was on early appendicectomy..$^{45}$ The incidence of wound infection in our patients was only $1.4 \%$ and includes those patients who developed wound infection after discharge. Although this is a non-randomised study, the two groups of patients were similar in age, sex, operative technique, and antibiotic treatment.

Sixty per cent of the patients from both the groups were discharged within three days. The difference in the average duration of hospitalisation is explained by the additional preoperative hospitalisation for the patients whose operation was delayed overnight.

The incidence of perforation, complications, and duration of hospitalisation was similar in both groups in our series. Although early appendicectomy remains the treatment of choice, it can be safely postponed overnight without increasing morbidity and mortality.

1 Buck N, Devlin HB, Lunn JN. The report of a confidential enguiry into perioperative deaths. London: Nuffeld Provincial Hospitals Trust and King's Fund Publishing Office, 1987.

2 Williams N, Kapila L. Appendicitis in the preschool child. Arch Dis Child 1991;66:1270-2.

3 Wyatt MG, Houghton PWJ, Brodribb AJM. Theatre delay for emergency general surgical patients: a cause for concem? Ann $R$ Coll Surg 1990;72:236-8. management. American Surgeon 1991;57:282-5.

5 Neilson IR, Laberge JM, Nguyen LT, Moir C, Doody D, Sonnino RE, et al. Appendicitis in children: Current therapeutic recommendations. $\mathcal{F}$ Pediatr Surg 1990;25:1113-6.

(Accepted 4 February 1993)
4 Maxwell JM, Regland JJ. Appendicitis. Improvement in diagnosis and 